Çanakkale Onsekiz Mart University, Journal of Graduate School of Natural and Applied Sciences, 2019:5,1, 112-119

Araştırma / Research

\title{
Spool İmalat Süreci Optimizasyonu
}

\author{
Bige Küçükefe ${ }^{*}$ \\ Namık Kemal Üniversitesi, Marmara Ereğlisi Meslek Yüksek Okulu
}

12.12.2018 Geliş/Received, 14.03.2019 Kabul/Accepted

\section{Özet}

Rafineri ve petrokimya tesislerinin kurulmasında boru sistemine ait bölümlerin (spool) fabrika ortamında imalatı son yıllarda tercih edilen bir yöntem olmuştur. Spool imalatı farklı boy ve miktarlarda boru ve bağlantı elemanı malzemelerinin kullanımını gerektirmektedir. Bir spool için kesilmesi gereken borular belirlenirken kayıp miktarının en az olması amaçlanmaktadır. Bu çalışmanın amacı, spool imalat sürecinde malzeme kayıplarını en aza indiren ve seçilen performans kriterini (spool sayısı veya Weld Dia Inch (WDI toplamı)) maksimize eden stok malzemenin belirlenmesidir. Gerçek bir fabrika için spool imalat sürecinin bütün aşamalarını kapsayan bir dijital dönüşüm projesinin parçası olan çalışmada, NP-hard kategorisinde yer alan optimizasyon probleminin çözümü için bir Monte-Carlo algoritması geliştirilmiştir. Geliştirilen yöntem ile minimum kayıp ile en uygun performans kriterini sağlayan malzeme planlaması (MRP) belirlenmektedir.

Anahtar Kelimeler: Monte Carlo, stok kesme problemi, stokastik optimizasyon

\section{Optimization of Spool Fabrication Process}

\begin{abstract}
Spool manufacturing in a workshop environment is a preferred method in recent years for refinery and petrochemical plants. Spool manufacturing involves cutting and welding pipe and fittings in different length and quantities. It is aimed to have the least amount of loss when determining pipes to be cut for a spool. The purpose of this study is to optimize stock material usage to maximize spool quantity or Weld Dia Inch (WDI) total depending on the selected performance criteria. As part of a digital transformation project that covers all stages of the spool manufacturing process for a real factory, a Monte-Carlo algorithm has been developed to solve the optimization problem in the NP-hard category. Material Resource Planning (MRP) which provides the best performance criterion with minimum loss, is determined with the developed method.
\end{abstract}

Keywords: Monte Carlo, cutting stock problem, stochastic optimization

\footnotetext{
*Sorumlu Yazar (Corresponding Author): Bige Küçükefe (e-posta:bkucukefe@nku.edu.tr)

Bu makale Namık Kemal Üniversitesi Teknoparkında faaliyet gösteren BigeSoft yazılım firmasının Katar'daki bir projesi sonucu yazılmıştır.
} 


\section{Giriş}

Proses borulama sistemlerini oluşturan kısımların (spool) bir fabrika ortamında imal edilmesi, rafineri ve petrokimya tesislerinin kurulmasında tercih edilen bir yöntemdir. $\mathrm{Bu}$ sayede sahada yapılması gereken boru kaynağı miktarı azalmakta ve dolayısı ile tesis kurulum süresi önemli oranda kısalmaktadır. Bu makalede, Katar'da faaliyet gösteren gerçek bir firma için spool imalat süreçlerinin takip edilmesi, optimum stok kullanımı, raporlaması ve kalite kontrol işlemlerinin elektronik kayıt altına alınması amacıyla geliştirilen bilgisayar yazılımı detaylı olarak sunulmaktadır. Spool Manager olarak adlandırılan yazılımın bileşenleri arasında, spool imalatı için atanacak stok malzemeyi optimum olarak belirlemeyi hedefleyen bir stokastik optimizasyon algoritması da yer almaktadır.

Stok kesme problemleri (SKP) literatürde önemli bir yer tutmaktadır. Bir optimizasyon problemi olarak NP-zor (Garey ve Johnson, 1979) sınıfında yer alan SKP'nin çözümü için pek çok sezgisel yöntem önerilmiştir (Wäscher ve Gau, 1996). Aynı uzunluktaki stok büyüklüklerinden farklı uzunluktaki parçaların kesimini ele alan çalışmalar (Eshgi ve Javanshir 2008; Cui ve Liu, 2011) literatürde yaygın olmakla birlikte, çoklu stok büyüklüklerinin çoklu boylarda tek boyutlu kesimine yönelik sınırlı sayıda araştırma vardır. Dikili ve ark. (2008) bir matematiksel model oluşturmadan farklı stok boyları kullanarak kayıp miktarını en aza indiren sezgisel bir yaklașım geliștirmişlerdir. Benzer șekilde Keskin (2015) ve Wascher ve ark. (2007) tarafından "Çoklu Stok Büyüklüklerinin Tek Boyutlu Kesim Problemi" şeklinde sınıflandırılan problem için iki aşamalı bir çözüm yöntemi önermiştir. İlk aşama sezgisel bir algoritma içerirken, ikinci aşamada bir tam sayılı doğrusal problemi modelinden yararlanılmıştır. Karelahti (2002) çelik endüstrisindeki kesme işlemini iki boyutlu bir modelin optimizasyon probleminin çözümü şeklinde ele almıştır. Berberler ve ark. (2011) ise problemin çözümü için bir dinamik programlama algoritması kullanmışlardır. Tanır ve ark. (2017) çelik sektöründeki birleşik stok kesme ve patern sıralama problemi için sezgisel bir algoritma kullanmışlardır.

Geliştirilen yazılım 4 ana modülden oluşmaktadır. Bu modüller; proje verilerinin veritabanına aktarılması, stok malzeme atama optimizasyonu, imalat ve kalite kontrol sürecine ait verilerin sisteme aktarılması ve raporlamadır. Bir ön çalışma ile belirlenen proje verileri sisteme aktarıldıktan sonra, spool imalatında kullanılacak stok malzemenin kayıplarını en aza indirecek şekilde optimum ataması gerçekleştirilir. Optimizasyon sürecinde öncelikle yaygın olarak kullanılan bir sezgisel yöntem ile referans optimum atamalar belirlenir. Sonrasında gerçekleştirilen stokastik optimizasyon çok sayıda farklı ve rastgele kombinasyon için kayıp değerlerini hesaplar ve sonuçlar sezgisel yöntemin sonuçları ile kıyaslanır. Stokastik optimizasyonun daha başarılı sonuçlar elde ettiği atamalar en uygun kabul edilerek yeni referans atama olarak alınır. Stokastik yöntem sonuçlarından daha iyi performans elde edilemez ise malzeme atamaları için sezgisel yöntem sonuçları kullanılır. Spool imalat ve kalite kontrol sürecine dair güncel bilgiler mobil cihazlar ile sisteme aktarıldıktan sonra gereksinim duyulan raporlar oluşturulur.

Bir spool boru ve bağlantı elemanları malzemelerinden oluşur. Optimizasyon ile boru kayıplarını en aza indirgeyen stok kullanımının belirlenmesi hedeflenirken, bağlantı elemanı atamalarında amaç en fazla spool sayısını elde etmek veya en fazla toplam kaynak miktarını (Weld Dia Inch, WDI) gerçekleştirmek olabilir. Seçilen kritere göre (spool sayısı veya toplam WDI) stokastik optimizasyon kullanılarak en uygun bağlantı elemanı atamaları belirlenir. Bu yöntemin başka bir avantajı da eksik malzeme nedeniyle imalatı tamamlanamayacak olan 
spool listesinin de elde edilmesidir. $\mathrm{Bu}$ sayede malzemesi tam olmayan spool imalatına başlanmayarak önemli faydalar sağlanır.

\section{Materyal ve Yöntem}

Spool imalat süreci özellikle büyük projeler için çok karmaşık bir yapıya sahiptir ve özel yazılım çözümlerinin geliştirilmesini gerektirir. Proje dokümanlarında gösterilen spool'ların fabrika ortamında imal edilmesi için izometri, spool, malzeme ve kaynak bilgileri ve ilişki yapıları bir veritabanında tanımlanmalıdır. Sonrasında, imal edilecek spool'lar için hangi stok malzemenin kulanılacağı kesme kayıplarını en aza indirmeyi amaçlayan bir algoritma ile belirlenmelidir. Boru seçimini takiben en fazla spool sayısı veya toplam WDI tercihine göre bağlantı elemanı malzemelerinin atamaları yapılmalıdır. Takip eden imalat ve kalite kontrol süreci mobil cihazlar kullanılarak hızlı ve hataları en aza indirecek bir şekilde yürütülmelidir. Son olarak, imalat sürecinin her aşaması için kapsamlı raporlama araçları mevcut olmalıdır. Bütün bu ihtiyaçları karşılayan hazır bir paket yazılımın ticari olarak sunulmaması nedeniyle firmaya özel bir yazılımın geliştirilmesi gerekmiştir.

Yöntem olarak kullanılan Monte Carlo stokastik optimizasyon modelinde, karar değişkenleri, kısıtlar ve amaç olmak üzere üç temel unsur bulunmaktadır. Kısıtları gerçekleştiren amaç fonksiyonunu maksimize ya da minimize eden karar değişkeni değerlerinin en iyi kombinasyonunu belirleme sürecine optimizasyon adı verilir. Optimal değerleri elde etmek için ise genellikle hedefe doğru ve tekrarlayan işlemlerden oluşan bir süreç gerektirmektedir. Bu süreç şu şekilde işler. İlk önce karar değişkenlerinin başlangıçtaki değerleri için amaç fonksiyonu değerleri hesaplanır, sonuçları analiz edilir, bir veya daha fazla karar değişkeninin değerleri değiştirilerek model tekrar çalıştırılır ve uygun bir sonuç bulana dek aynı işlemler tekrarlanır.

\section{Yazılım}

Proje dokümanlarına dayanarak mühendislik ekibince hazırlanan veri girişlerinin içerdiği bilgiler Çizelge 3.1'de verilmektedir.

Çizelge 3.1. Veritabanı Proje Veri Alanları

\begin{tabular}{|c|c|}
\hline & Veri Alanları \\
\hline İzometri & $\begin{array}{l}\text { Proje No, İzometri No, Hat No, Alan, Revizyon, Öncelik, Boya, Malzeme, } \\
\text { Bitmesi gereken tarih, Not }\end{array}$ \\
\hline Spool & Spool No, İzometri No, Boya alanı, Boya, Boru sınıfi, Öncelik, Not \\
\hline Malzeme & $\begin{array}{l}\text { Malzeme No, Tip (Boru veya Bağlantı Elemanı), Açıklama, Çap, Birim ağır- } \\
\text { lık, Malzeme, Not }\end{array}$ \\
\hline MTC & Spool No, Nokta, Malzeme Kodu, Miktar, Not \\
\hline $\begin{array}{l}\text { Kaynak } \\
\text { Bilgisi }\end{array}$ & $\begin{array}{l}\text { Kaynak No, Spool No, Kategory, Pozisyon-1, Pozisyon-2, Kaynak Tipi, } \\
\text { WDI, Not }\end{array}$ \\
\hline Stok Bilgisi & Stok No, Malzeme No, İlk miktar, Kalan miktar, Proje No, Not \\
\hline
\end{tabular}


Çizelge 3.1'de yer alan proje verileri sisteme aktarıldıktan sonra, stok malzeme ataması için gerekli olan bilgiler tamamlanmış olur. Aşağıda boru ve bağlantı elemanı atama işlemi için kullanılan optimizasyon yöntemi açıklanmaktadır. Atama sonrasında başlayan imalat ve kalite kontrol süreci için veri girişinde mobil cihazlar kullanılır ve bu sayede kağıt formlar ve ikincil veri girişi ihtiyacı ortadan kalkar.

Raporlama modülü ise spool imalat sürecinin her aşamasında gerekli olan bilgilere erişimi sağlar. Dinamik filtreleme seçeneklerinin de yer aldığı raporlama modülünün yanı sıra kritik performans değerlerini (KPI) gösteren içerikler de geliştirilen yazılımda yer almaktadır.

\section{Optimizasyon Yöntemi}

İşletmenin kullanmakta olduğu sezgisel yaklaşım ile gerçekleştirilen atama işlemlerinde, her bir spool için gerekli olan boru boyları toplu olarak listelenip büyükten küçüğe doğru sıralanmakta ve sonrasında stokta bulunan borulara atanmaktadır. Geliştirdiğimiz optimizasyon yöntemi ile birincil amacımız işletmenin kullandığı sezgisel yaklaşıma kıyasla daha az kayıp sağlayan atama işlemi gerçekleştirmektir. Bu nedenle, optimizasyon algoritması stokastik olarak belirlediği atama işlemleri sonucu hesaplanan kayıp miktarını başlangıçta sezgisel yaklaşım ataması ile karşılaştırmaktadır. Stokastik optimizasyon algoritmasında daha az bir kayıp elde edildikten sonra yeni optimum atama olarak belirlenmekte ve takip eden simulasyonlar yeni optimum atama ile kıyaslanmaktadır.

\subsection{Sezgisel Yaklaşım}

Sezgisel yaklaşım yöntemi takip eden adımlardan oluşmaktadır.

Adım-1: İmal edilecek Spool'lar listelenir.

Adım-2: Spool'ları oluşturan boru parçaları her boru tipi için büyükten küçüğe sıralanır.

Adım-3: Stokta bulunan borular, Adım-2'deki sıraya göre kesilir ve her boru tipi için kayıp miktarı hesaplanır $(K)$

\subsection{Stokastik Optimizasyon (Boru Ataması)}

Sezgisel yaklaşım yöntemi ile belirlenen atama sonucu oluşan kayıp miktarı başlangıç optimum olarak kabul edilerek bir stokastik simülasyon yapılır.

Adım-1: İmal edilecek Spool'lar listelenir.

Adım-2: Stokta bulunan borular tiplerine göre listelenir.

Adım-3: Her bir spool için gerekli olan boru parçaları, rastgele olarak atanır ve bu şekilde bütün atamalar tamamlandıktan sonra oluşan kayıp miktarı hesaplanır $\left(\mathrm{K}_{\mathrm{S}}\right)$. Eğer $\mathrm{K}_{\mathrm{S}}$ değeri $\mathrm{K}$ değerinden küçük ise, bunu sağlayan atama yeni optimum olarak kabul edilir $\left(K=K_{S}\right)$ ve belirlenen simülasyon sayısı tamamlanana kadar bu işleme devam edilir.

\subsection{Stokastik Optimizasyon (Bağlantı Elemanı Ataması)}

Hesaplanan optimum boru ataması kullanılarak, her bir spool için gerekli olan bağlantı elemanı malzemesi için stok ataması rastgele olarak belirlenen sayıda yapılır ve her simulasyon için toplam Spool sayısı ve toplam WDI hesaplanır. İşletmenin tercihine göre en fazla spool sayısı veya toplam WDI elde edilecek üretim planlaması bu sayede belirlenebilir. Bu yöntem ile bağlantı elemanı atamasının başka bir avantajı, eksik bağlantı elemanı malzemesinin spool imalatına başlanmadan önce tespit edilebilmesidir. 
Kulllanılan algoritmanın sözde kodu aşağıda verilmektedir.

$B A S \zeta L A$

$O K U$ Spool Listesi, Stokta bulunan borular

KAYIPLAR-1 sezgizel yöntem

KAYIPLAR-2 rastgele yöntem (BÜTÜN OLASILIKLAR)

E $\breve{G} E R \quad$ KAYIPLAR-2 < KAYIPLAR-1

DEĞILLSE

$A T A M A=$ rastgele yöntem atamas1

$A T A M A=$ sezgisel yöntem atamas 1

TOPLAM SPOOL = rastgele yönteme atamast-1 ILE TOPLAM SPOOL (ATAMA)

TOPLAM WDI = rastgele yönteme atamast-2 ILE TOPLAM WDI (ATAMA)

EĞER TOPLAM SPOOL MOD

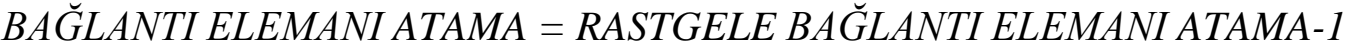
$D E \breve{G} \dot{I} L S E$

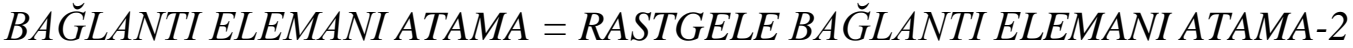

\section{5. Örnek Uygulama}

Geliştirilen optimizasyon algoritmasını test etmek için Şekil 5.1'de gösterilen spool imalatı kullanılacaktır. 3 adet spool için stokta $6000 \mathrm{~mm}$ uzunluğunda 4 adet boru ve 2 adet Tbağlantı elemanı (T-Fit) bulunmaktadır. İmalatın tamamlanabilmesi için gerekli olan malzeme listesi aynı şekilden çıkarılabilir. 3 adet spool imalatının tamamlanabilmesi için 4 adet Tbağlantı elemanı gerekli iken stokta 2 adet mevcuttur. İlk olarak sezgisel yöntem yardımıyla stok atamaları yapıldıktan sonra, bu şekilde ortaya çıkan kayıp referans optimum alınarak stokastik optimizasyon ile kayıpların daha az olduğu atamalar bulunmaya çalışılacaktır. Son aşamada ise, toplam spool sayısı veya toplam WDI kriterlerine göre bağlantı elemanı atamalar1 yapilacaktır.

\begin{tabular}{|l|l|l|}
\hline $6000 \mathrm{~mm}$ & $6000 \mathrm{~mm}$ & $6000 \mathrm{~mm}$ \\
\hline Stok & $6000 \mathrm{~mm}$ T-Fit T-Fit \\
\hline
\end{tabular}

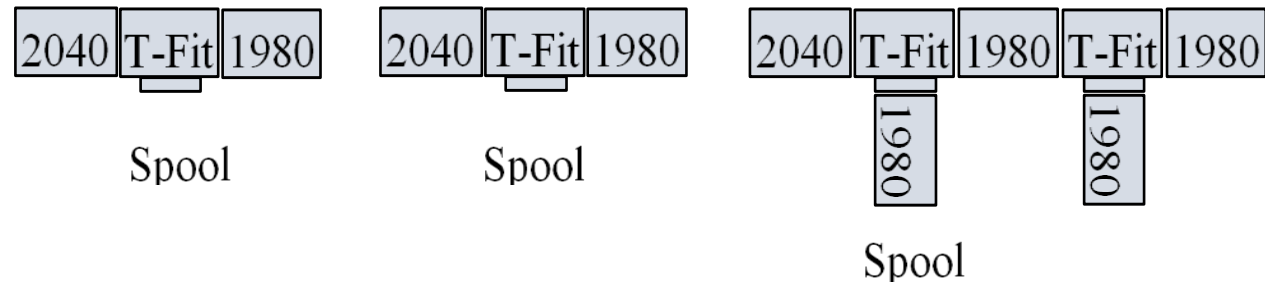

Şekil 5.1. Örnek uygulama için imal edilecek 3 adet spool ve stok durumu. (Bütün boru boyları mm'dir)

Sezgisel Yöntem: Spool boru parçaları boy olarak büyükten küçüğe doğru sıralanırlar. 20402040-2040-1980-1980-1980-1980-1980-1980. Sonrasında stokta bulunan borular önceki belirlenen sıraya göre kesilirler. Çizelge 5.1 'de bu işlem sonrası oluşan atama ve boru kayıp 
boyları verilmektedir. Sezgisel yöntem ile yapılan atamalar neticesinde $1920 \mathrm{~mm}, 60 \mathrm{~mm}$ ve $4020 \mathrm{~mm}$ boru parçaları şeklinde toplamda $6000 \mathrm{~mm}$ kayıp oluşmaktadır.

Çizelge 5.1. Sezgisel yöntem ile yapılan stok atamaları sonrası kesilen boru parçaları ve kayıplar

\begin{tabular}{|l|c|l|l|}
\hline Stok & Orijinal Boy $(\mathrm{mm})$ & Kesilen Parçalar $(\mathrm{mm})$ & Kayı $(\mathrm{mm})$ \\
\hline Boru-1 & 6000 & 2040,2040 & 1920 \\
\hline Boru-2 & 6000 & $2040,1980,1980$ & 0 \\
\hline Boru-3 & 6000 & $1980,1980,1980$ & 60 \\
\hline Boru-4 & 6000 & 1980 & 4020 \\
\hline
\end{tabular}

Stokastik Optimizasyon: Sezgisel yöntem ile elde edilen kayıp değerleri başlangıç referansı kabul edilerek gerçekleştirilen stokastik optimizasyon sonucu hesaplanan boru atamaları Çizelge 5.2'de yer almaktadır. Görüleceği üzere, stokastik optimizasyon ile hiçbir kayıp oluşmamıştır. Bir boy boru hiç kesilmeden stokta kalmıştır. Bu sayede önemli bir tasarruf elde edildiği gibi, ilk aşamada 3 boy borunun stokta bulunması durumunda sezgisel yöntem ile tamamlanamayacak olan 3 adet spool imalat,, stokastik optimizasyon kullanılarak eksiksiz tamamlanabilir.

Çizelge 5.2. Stokastik Optimizasyon ile yapılan stok atamaları sonrası kesilen boru parçaları ve kayiplar

\begin{tabular}{|l|c|l|c|}
\hline Stok & $\begin{array}{l}\text { Orijinal } \\
(\mathrm{mm})\end{array}$ & Kesilen Parçalar (mm) & Kayıp (mm) \\
\hline Boru-1 & 6000 & $2040,1980,1980$ & 0 \\
\hline Boru-2 & 6000 & $2040,1980,1980$ & 0 \\
\hline Boru-3 & 6000 & $2040,1980,1980$ & 0 \\
\hline Boru-4 & 6000 & - & 0 \\
\hline
\end{tabular}

Bağlantı Elemanı Ataması: Boru atamaları sonrası bağlantı elemanı atamaları gerçekleştirilir. Burada işletmenin önceliği, proje hakediş koşullarına bağlı olarak, en fazla sayıda spool imalat1 yapmak veya toplam WDI (kaynak) gerçekleştirmek olabilir. Bu önceliklere göre üretim planlaması yapılmalıdır. Aynı zamanda, stokta bulunan bağlantı elemanlarının bütün spool imalatını tamamlamak için yeterli olmaması durumunda tercih edilen performans kriterine göre belirlenen spool'lar öncelikle imal edilmelidir. Çizelge 5.3'te bağlantı elemanı atama sonuçları verilmektedir. 
Çizelge 5.3. Stokastik Optimizasyon ile yapılan bağlantı elemanı atamaları

\begin{tabular}{|l|l|c|c|}
\hline $\begin{array}{l}\text { Performans Kri- } \\
\text { teri }\end{array}$ & Spool İmalat Siras1 & Tamamlanan Spool Say1s1 & Toplam WDI \\
\hline $\begin{array}{l}\text { En fazla spool } \\
\text { sayı1 }\end{array}$ & $\begin{array}{l}\text { Spool-1, Spool-2, } \\
\text { Spool-3* }\end{array}$ & 2 & 4 \\
\hline $\begin{array}{l}\text { En fazla WDI } \\
\text { (kaynak) }\end{array}$ & $\begin{array}{l}\text { Spool-3, Spool-1* } \\
\text { Spool-2* }\end{array}$ & 1 & 6 \\
\hline
\end{tabular}

*: Bağlantı elemanı malzemesi eksik olduğu için tamamlanamayacak spool. İmalatın sonraki aşamasına bırakıldığı için geçen süre içerisinde eksik bağlantı elemanı malzemesi tedarik edilebilir.

\section{Sonuç}

Katar'da bulunan gerçek bir işletme için geliştirilen spool imalat süreci takip ve raporlama yazılımının modüllerinden biri spool imalatı için kesilecek borularda kayıpları en aza indirmeyi hedeflemektedir. Ayrıca, bağlantı elemanı atamalarının en fazla spool sayısı veya toplam kaynak (WDI) miktarını sağlayacak şekilde yapılması gerekmektedir. Stokastik optimizasyon kullanılarak gerçekleştirilen stok malzeme atamalarının sezgisel yönteme göre daha başarılı olduğu görülmüştür. Atama simulasyonu bütün olası atama kombinasyonlarını değerlendirmeyi amaçlamakla birlikte, büyük boyutlu projelerde hesaplama süresinin çok uzaması nedeniyle bütün atama olasılıkları değerlendirilememektedir. Spool imalatının tamamlanabilmesi için gerekli olan eksik malzemenin belirlenmesi yazılım modülünün işletmeye sağladığı ayrı bir faydadır. Bu sayede eksik malzemeler önceden tedarik edildiği gibi malzemesi tam olmayan spool imalatlarına başlanmayarak sürecin yarım kalmasının önüne geçilmektedir. Optimizasyon algoritmasının sonuç verebilmesi için ihtiyaç duyulan ilişkisel veriler (spool bilgisi, stok bilgisi, malzeme bilgisi ve proje bilgisi) bir veritabanından alınmaktadır. 


\section{Kaynakça}

Berberler M. E., Nuriyev U., Yıldırım A. 2011. A Software For The One-Dimensional Cutting Stock Problem. Journal of King Saud University - Science 23: 69-76.

Cui Y., Liu Z. 2011. C-Sets-Based Sequential Heuristic Procedure For The One-Dimensional Cutting Stock Problem With Pattern Reduction. Optimization Methods and Software, 26:637-645.

Dikili A. C., Takinac1 A. C., Pek N. A., 2008. A New Heuristic Approach To OneDimensional Stock-Cutting Problems With Multiple Stock Lengths In Ship Production. Ocean Engineering 35: 637-645. https://doi.org/10.1016/j.oceaneng.2008.01.003

Eshghi K., Javanshir H. 2008., A Revised Version Of Ant Colony Algorithm For OneDimensional Cutting Stock Problem, International Journal of Industrial Engineering : Theory Applications and Practice 15: 341-348.

Garey M. R., Johnson D. S., 1979. Computers and Intractability; A Guide to the Theory of NP-Completeness. Computers and Intractability.

Karelahti J., 2002. Solving The Cutting Stock Problem In The Steel Industry. Master's Thesis. Helsinki University Of Technology.

Keskin F. D. 2015. Tek Boyutlu Kesme Problemi : Bir İşletme Uygulaması. Gazi Üniversitesi İktisadi ve İdari Bilimler Fakültesi Dergisi 15: 180-196.

Tanır D., Uğurlu O., Kapar M., Nuriyev U., 2018. "Birleşik Stok Kesme ve Patern Sıralama Problemi için Bir Sezgisel Algoritma", Süleyman Demirel Üniversitesi, Fen Bilimleri Enstitüsü Dergisi 22:300-305.

Wäscher G., Gau T., 1996. Heuristics For The Integer One-Dimensional Cutting Stock Problem: A Computational Study, OR Spektrum18:131-144

Wäscher G., Haußner H., Schumann H., 2007. An Improved Typology Of Cutting And Packing Problems, European Journal of Operational Research 183:1109-1130. 